\title{
Fire Distribution in Fleet Air Defense Missile Network Collaboration
}

\author{
Cai Jing Biao \\ Navy Equiqment Research Institute \\ Beijing, China \\ e-mail: 446982051@qq.com \\ Zheng Yi \\ Navy Equiqment Research Institute \\ Beijing, China \\ e-mail: 37630759@qq.com
}

\author{
Feng Wei Qiang \\ Navy Equiqment Research Institute \\ Beijing, China \\ e-mail: 285892287@qq.com
}

\begin{abstract}
It is the key to assure and optimize the firepower allotment for the network centric ship-to-air missile, which can improve the whole air defense warfare capability of surface vessels formation. For the purpose of take the advantage of The Network Centric Ship-to-air Missile, under the condition of earlier damage, combining the character of the ship-to-air missile system, set up a model for the antimissile Fire Distribution of The Network Centric Ship-to-air Missile, which can balance the damage probability and the damage time.
\end{abstract}

Keywords-earlier damage; the Network Centric Ship-to-air Missile; fire distribution; air defense; damage probability

\section{INTRODUCTION}

Ship to air missile networked collaborative antimissile refers to break original platform centered traditional firepower unit structure, each function system is decomposed into independent operational node, the use of information communication network will be the operations within the regional operations node together as an organic whole. Making full use of and play the function of each operation node and advantage can improve overall system response time air defense combat, enhance the overall combat effectiveness of the ship to air missile weapon system ${ }^{[1]}$. In this new mode, the cooperative engagement between defense penetration can fully, achieve information into a decision, eventually translate into fire advantage ${ }^{[2]}$. Early damage refers to the incoming air targets allocation of the right type and amount of firepower unit and for each firepower unit planning the right shooting time, which ensures to meet the requirements of mutilate instantaneous before to expect the kill probability of intercept the target. How to realize the early damage? At the same time, ensure the maximum damage probability is difficult in ship to air missile networked collaborative antimissile.

It has been learnt from the related literature in recent years [3-8] that weapons fire distribution model is not only a single weapon type, but also a variety of weapon types; the fire channel number and the same number of targets also have a number of difference; There are only allowed a single shooting and judgment effect after the second shot; There are static allocation and dynamic allocation. Research assumptions, research perspective, research methods and evaluation indexes are diverse, although scholars at home and abroad do a lot of research work, there are still many aspects of the research work is relatively lack or not enough in-depth ${ }^{[9]}$. The traditional fire distribution technology considers a single factor (maximum damage to target or loss of the smallest unit), consider mutilate targets at the same time, many factors such as literature are less combat unit. Considering the damage both instantaneous and kill probability index, this paper establishes a kind of ship to air missile system based on the early damage of networked collaborative missile model, and it also verifies by an example. To improve the information under the condition of ship fleet anti-air theory is of great significance.

\section{THE CHARACTERISTICS OF SHIP TO AIR MISSILE NETWORKING COMBAT}

The advantages of ship to air missile network-centric operation lies in the system of single component failure will not lead to the failure of system as a whole, to enhance the robustness and capability of the system. In addition, through the defense penetration between network and, with the missile guidance radar network, form the network topology structure, can from any location on the guidance radar control conditions to the target through the network to implement interception of ship to air missile weapon system. Ship to air missile system requires at least meet the following two index ${ }^{[10]}$ : (1) interconnection, system between each component can be meaningful real-time communication. interoperability can communicate with each other between each component in the system, and the content of the communication can be understood and dealt with. Ship to air missile system is to get all aspects of air defense (the physical domain, information domain, cognitive domain) links to a Shared situational awareness and common understanding command intention, achieves the combat effect of unity and synchronization, by obtaining better synchronization effect in the war room, reduces system response time of warfare, enhances the ability to intercept, and improves the ability to survive. 
Ship to air missile networked system consists of three parts related to each other through communication network subnet: early warning detection network, command and control network and intercept war network. Early warning detection is mainly to complete the target detection, tracking, and target designation; Command and control is mainly to data fusion of target data, provides a unified battlefield awareness, and is responsible for the formulation and releases operational decisions; Intercept the warring webmaster, if the instructions are according to the launch and guided missile interceptor targets. Described in this paper, the system is made up of early warning detection network, command and control network and intercept war network three subnets of ship to air missile air defense network system. System main characteristic is in weapon system between the number and types of the more complex, subnet matching each other greatly affects the combat effectiveness. First of all, the early warning detection net and the effective power of command and control network zone should overlap. It can command and control network using the early warning target information obtained from the early warning detection network increases the probability of finding goals, shortens the time of the found targets, so as to express the advantages of weapons networking. Otherwise, the command and control network is equivalent to run independently. Secondly, command and control network and the intercept war network should be large areas of overlap, making track be into position to attack. In this way, the effective power of command and control network and intercept war network range can be used efficiently.

\section{BASED ON THE EARLY DAMAGE OF SHIP TO AIR MISSILE NETWORKED COLLABORATIVE ANTI-MISSILE FIRE DISTRIBUTION MODEL}

\section{A. the establishment of the mathematical model}

Ship to air missile system constant of multiple of ship to air missile weapon system in fleet. By sharing charges system,they launch platform and target designation system, form the different types of ship to air missile anti-missile weapon system together. In this variety of ship to air missile for multiple air targets intercept, fire distribution content should include two aspects:(1) distribution of weapons, for each target allocation of the right type and number of ship to air missile; (2) the shooting time distribution, the distribution of weapons, on the basis of planning the shooting time, set up fire window, to damage the incoming target as soon as possible.(3) the classification of firepower unit.According to the firepower unit damage time and kill probability of target classification fire power unit as shown ${ }^{[11]}$.

$N=\{n ; n=1,2, \cdots, N\}$ On incoming can target a certain probability for a collection of firepower unit mutilate, here specifically to ship to air missile weapon system;

$$
N_{1}=\left\{n ; t_{n l}<t_{h s}\right\} \subset N \quad \text { is } \quad \text { instantaneous }
$$

$t_{h s}$ (including $t_{h s}$ ), as expected before, can be according to the most damage probability and damage to targets set of firepower unit;

$$
N_{2}=\left\{n ; t_{n M}<t_{h s}\right\} \subset N_{1} \text { is instantaneous } t_{h s}
$$

(including $t_{h s}$ ) as expected before, can be according to the most damage probability and damage to targets set of firepower unit;

$$
N_{3}=N_{1} \backslash N_{2} \text { is instantaneous } t_{h s} \text { (including } t_{h s} \text { ), }
$$

before not according to the most damage to targets, set fire unit damage;

$$
N_{4}=\left\{n ; t_{n l}<t_{h s}, \alpha_{n}=-1\right\} \subset N \quad \text { Instantaneous }
$$
(as expected before, and not to participate in shooting firepower unit;

$$
N_{5}=\left(N \backslash N_{1}\right) \cup N_{4} \text { is the remainder of the fire }
$$
distribution to meet expectations index after firepower unit.

(4) the kill probability of weapon system

At any instant $t$ of weapon systems with $N$ firepower unit under the kill probability of target can be expressed as follows:

$$
\begin{aligned}
& P(t, \alpha)=1-\prod_{n=1}^{N}\left[1-P_{n}(t)\right] \\
& =1-\prod_{n=1}^{N}\left\{1-P_{n}\left(\alpha_{n} \cdot l\left[t-t_{n}\left(\alpha_{n}\right)\right]\right)\right\}
\end{aligned}
$$

In the type (1):

$l[t]$ is the unit step function; $n$ is to mutilate instantaneous first appeared successively for sequence of firepower unit number.

$$
\alpha=\left(\alpha_{1}, \alpha_{2}, \cdots, \alpha_{n}, \cdots, \alpha_{N}\right) \text { is for shooting in }
$$

advance coefficient, its value is used to determine the forecast mutilate instantaneous firepower unit, and computation formula is as follows:

$$
t_{n}=\alpha_{n} t_{n L}+\left(1-\alpha_{n}\right) t_{n M}
$$

In the type (2), $\alpha_{n} \in[0,1]$ or $\alpha_{n}=-\infty$

Once it is obtained, Type (2) can be the first firing instantaneous unit. When $\alpha_{n} \in[0,1]$, corresponding to the first single firepower unit is selected, and the greater $\alpha_{n}$, the sooner its firing instantaneous; When $\alpha_{n}=-\infty$, the equivalent of said first a firepower unit has not been selected, that is, the unit is not used in the shooting of the target.

A satisfied for each $\alpha_{n}$ decision value, which determines the damage of all firepower unit also had completed the task of fire distribution, thus the task into a decision $\alpha_{n}$. Convenience is provided for calculating the properties $\alpha_{n}$.

$$
\begin{aligned}
& \text { If } \alpha \equiv 0 \text {, then: } \\
& P_{\max }=1-\prod_{n=1}^{N}\left\{1-P_{n}\left[D_{q n}\left(t_{n M}\right)\right]\right\}
\end{aligned}
$$

At this point, it is equal to the maximum under the kill probability of fire distribution.

If $\alpha \equiv 1$, then:

$$
P_{\min }=1-\prod_{n=1}^{N}\left\{1-P_{n}\left[D_{q n}\left(t_{n L}\right)\right]\right\}
$$


At this point, the equivalent of fire distribution under the damage at the earliest opportunity. The former may delay the aircraft, the latter may have lost fire intensity.

\section{B. fire distribution rules}

For both kill probability and two measures of early destruction, put forward the following firepower allocation algorithm:

(1) follow the incoming target threat degree of size distribution of firepower unit in turn.

(2) priority threat degree big goals that meet the following objective functions: before the expectations of the instantaneous $t_{h s}$, guarantee the kill probability $P\left(t_{h s}, \alpha\right)$ in the closest way than expected value $P_{h s}$, namely, under the constraints of $P\left(t_{h s}, \alpha\right) \geq P_{h s}$ the optimization model is set up:

$$
\min _{\alpha \in[0,1]}\left\{P\left(t_{h s}, \alpha\right)-P_{h s}\right\} \geq 0
$$

$t_{h s}$ And $P_{h s}$ can be determine by the value of the visual battlefield situation, when $P_{h s}, t_{h s}$ is missing, or $P\left(t_{h s}, \alpha\right) \geq P_{h s} \quad, \quad$ can use the default values: $P_{h s}=P\left(t_{h s}, \alpha\right), t_{h s}=+\infty$.

(3) at the time of the target distribution firepower unit, if there are remaining firepower unit, it should be according to of firepower unit of the size of the shooting threat degree is firepower optimization.

(4) after all targets meet the expected damage index, the remaining unit of principles as follows:

Default value is used, according to the degree of threat bigger priority principle, with a given $\left\{\alpha_{n}\right.$, $\left.\alpha_{m} ; n \in N_{2}, \quad \mathrm{~m} \in N_{3}\right\}$ value assigned to the corresponding target; If it is missing, optional $\alpha_{m}=\alpha_{n}=1$.

\section{C. ship to air missile kill probability of target characteristics analysis}

Ship to air missile weapon system damage zone each point missile kill probability is affected by the large number of random factors. These factors are: shooting conditions, the guidance error, the performance parameters of fuze and warhead power parameters, characteristics, target vulnerability of fuze-warhead coordination, etc. Due to the comprehensive use of these factors, the killer areas such as killing probability curve complexity and diversity.

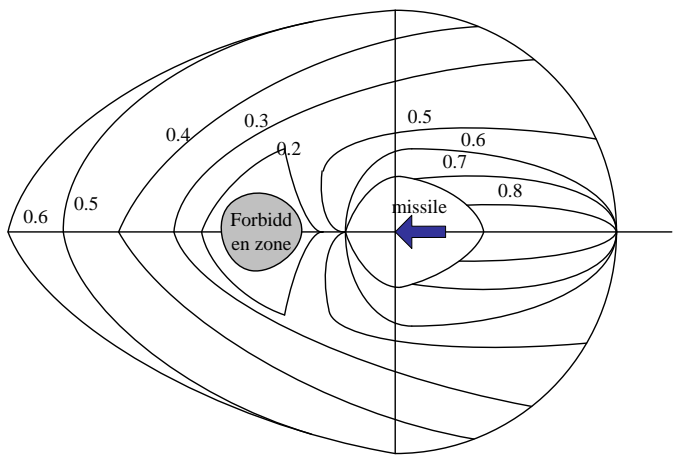

Figure 1. the anti-missile's kill probability distribution

The shaded part in the graph is the kill probability of missile damage area is less than 0.2.

\section{EXAMPLE ANALYSIS}

Ship to air missile system have 6 firepower unit which intercepted 2 incoming target $\mathrm{A}$ and $\mathrm{B}$, the threat of target A value is greater than the threat of $\mathrm{B}$ value. Request to expect to kill probability $P_{h s}=0.85$, the intercept of A target before $t_{h s}=20 s$, expecting to kill probability $P_{h s}=0.80$ the intercept of A target before $t_{h s}=30 \mathrm{~s}$. According to degree of threat big priority principle, the first to target A distribution of firepower unit and shooting opportunity, there are 5 firepower unit to meet the conditions of interception to target $\mathrm{A}$ that is $N=\{1,2,3,4,5\}$, each unit of the damage probability and damage time relationship curve is shown in figure 2.

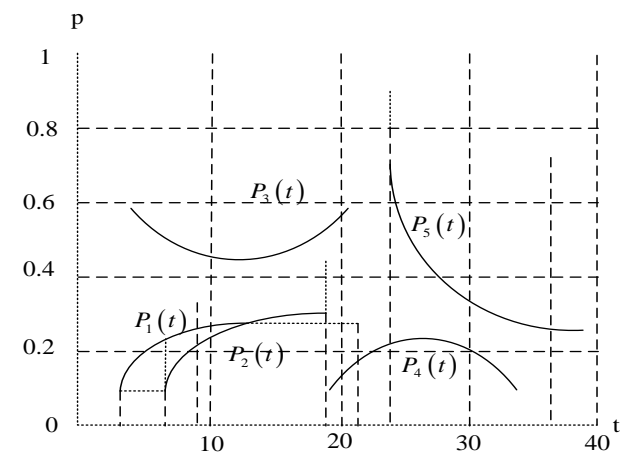

Figure 2. the anti-missile's damage probability for target A

All the firepower unit to target A mutilate instantaneous biggest and earliest and largest and earliest kill probability as shown in Table 1 . 
TABLE I the moment and the probability of the earliest and maximum damage for target A

\begin{tabular}{llllll}
\hline$n$ & 1 & 2 & 3 & 4 & 5 \\
\hline$t_{n l}(s)$ & 2.5 & 6.2 & 3.7 & 18.7 & 23.7 \\
\hline$t_{n M}(s)$ & 12 & 17 & $\begin{array}{l}3.7 \\
21.2\end{array}$ & 26.2 & 23.7 \\
\hline$P_{n L}$ & 0.12 & 0.15 & 0.58 & 0.21 & 0.7 \\
\hline$P_{n M}$ & 0.30 & 0.33 & 0.58 & 0.21 & 0.7 \\
\hline
\end{tabular}

From Figure 2 and Table $1, N_{1}=\{1,2,3,4\}$, $N_{2}=\{1,2,3\}, \quad N_{3}=\{4\} ; \quad P_{4}\left(t_{h s}\right)=0.13$

By (2) calculation $\alpha_{m}$,

$m \in N_{3}$ can get: $\alpha_{4}=0.342$.

$P^{*}=P\left(t_{h s}, \alpha_{m}, \alpha_{n}=0 ; m \in N_{3}, n \in N_{2}\right)$

$=0.87>P_{h s}$

Due to less firepower unit, using the method of ergodic seeking, when

$$
N_{4}=\{2\}
$$$$
P^{*}=P\left(t_{h s}, \alpha_{m}, \alpha_{n}=0, \alpha_{p}=-\infty ; m \in N_{3} \backslash N_{4}\right. \text {, }
$$

$\left.n \in N_{2} \backslash N_{4}, p \in N_{4}\right)=0.876$

And $P^{*}-P_{h s} \quad$ is the minimum, $P^{*}=P\left(t_{h s}, \alpha_{m}, \alpha_{n}=1, \alpha_{p}=-\infty\right.$,

$\left.m \in N_{3} \backslash N_{4}, n \in N_{2} \backslash N_{4}, p \in N_{4}\right) \quad$.By the calculation,

$=0.84<P_{h s}$

when $\alpha_{1}=0.89, P^{*}=P_{h s}=0.82$.

Distribution of all finished, before A implementation of firepower unit $N_{1} \backslash N_{4}=\{1,3,4\}$ for damage to the target.

By Type (2) calculate the firepower unit mutilate instantaneous is respectively:

$t_{1}=2.17 \mathrm{~s}, t_{3}=t_{4}=t_{h s}=20 \mathrm{~s}$.

At the end of the moment $t_{c h}$ on the target of fire distribution, remain firepower $\{2,5\}$ unit to target A fire to intercept.

Repeat the above steps, the target $\mathrm{B}$, firepower $\{2,5,6\}$ unit can be effective for the damage, the damage probability and damage time curve is shown in Figure 3.

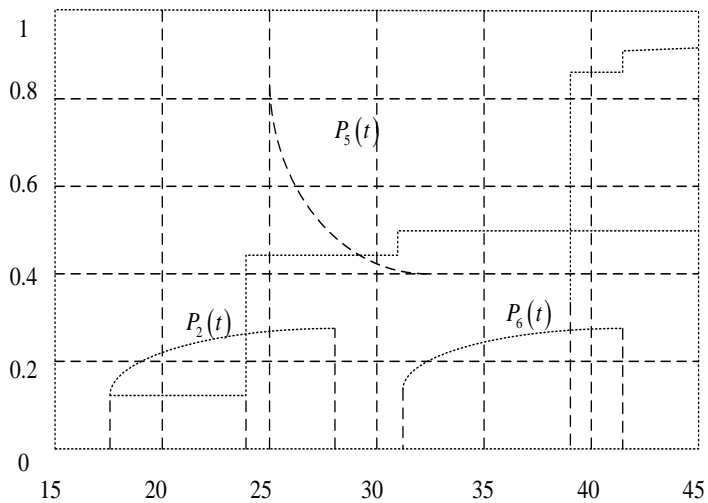

Figure 3. the anti-missile's damage probability for target B

All the firepower unit to target the earliest, most damage of instantaneous and the earliest and largest kill probability as shown in table 2 .

TABLE II the moment and the probability of the earliest and maximum

\begin{tabular}{llll}
\multicolumn{4}{c}{ damage for target B } \\
\hline$n$ & 2 & 5 & 6 \\
\hline$t_{n l}(s)$ & 17.2 & 23.7 & 31.2 \\
\hline$t_{n M}(s)$ & 28 & 23.7 & 42 \\
\hline$P_{n L}$ & 0.14 & 0.81 & 0.13 \\
\hline$P_{n M}$ & 0.32 & 0.81 & 0.31
\end{tabular}

By the Figure 3 and Table 2, $N_{1}=\{2,5\}$, $N_{2}=\{2\}, \quad N_{3}=\{5\}, \quad$ the firepower unit for the use of interception is $\{2,5\}$, when the shooting in advance coefficient respectively $\alpha_{2}=0, \alpha_{5}=0.67$, then $P^{*}=P_{h s}=0.80$.

All the firepower unit mutilate instantaneous respectively:

$$
t_{2}=t_{2 M}=28 s, t_{5}=23.7 \mathrm{~s}
$$

End of the fire distribution of the target of all, the remaining firepower unit $\{6\}$ set to idle state.

The above examples, based on the early damage of ship to air missile networked collaborative anti-missile fire distribution model, under the condition of satisfy ing expect kill probability of target, optimize the firepower unit damage time both the early together and in the actual fleet air defense combat, which can better play to the ship to air missile networked collaborative anti-missile combat effectiveness.

\section{CONCLUSION}

Based on the early damage of fire distribution, it is not only for each target allocation of the right type and amount of firepower unit, but also includes planning for each firepower unit at the same time which is the right shooting time, which can guarantee to meet the requirements of mutilate instantaneous before to expect the kill probability of intercept the target, and can achieve a better balance between damage probability and damage the timing, so as to establish a joint combat target function. Follow-up work to different features of the kill probability 
of ship to air missile weapon system research, under the rule of the early damage, finds synergy anti-missile optimal ship to air missile weapon system and networking and takes maximum operational effectiveness of the ship to air missile network system.

\section{REFERENCES}

[1] Galay Barbarosoglu , Linet Ozdamar, Ahmel Cevik.An Interactive Appmach of Hierarchical Analysis of Helicopter Logistics in Disaster Relief Operations[J]. European Journal of Operational Research, $2002: 118-133$

[2] WANG Hong-jun, CHI Zhong-xian.Shipboard hard and soft weapon anti-missile decision-makingoptimization based on collaboration[J], Control and Decision, 2007, 22 (3) : 299303

[3] Liang Bo, Duan Ran.Fire distribution model based on feasible direction algorithm[J], Command Information System and Technology, 2013,4 (2) :30-32

[4] L Ozdamar . Emergency logistics planning in natural disasters[J]. Annal of Operation Research, 2004, 129(11) : 218-219.

[5] Sarit Kraus.Negotiation and cooperation in mulfi-ageat environments.Artificial Intelligence. 1997 : 79-97
[6] HUANG Haixin, WANG Ding wei.English auction dynamic model based on fuzzy game[J], Information and Control,2012,41(4):509-513

[7] Shao Qiu feng, Ma ya long, hu jin chuan.Applied research for fuzzy composite operators in operational alternatives integrated evaluation[J],Journal of Academy of Armored Force Engineering, 2004, 18 (12) : 41-43

[8] LI Zi fen, LI Xiang min, CHEN Jin zhu.Dynamic joint fire distribution method based on decentralized cooperative auction algorithm[J],Fire Control \& Command Control , 2012,37 (11) :50-52

[9] NIAN Song lei, YAN Jian gang, CHEN Rong.The optimization method of antiship missile fire distribution based on dynamic programming[J],Ship Science And Technology, 2012,34 (7) :110-113

[10] MA Liang, QING Zuo-sheng, ZHANG Lin.Formation comprehensive cooperative air defense multi-stage decision optimization modeling[J], Tactical Missile Technology, 2013,9 (5) $: 25-28$

[11] CHEN Guo sheng, JIA Zi ying.Research on coordinated air defense firepower distribution model for warships[J], Command ControI\& Simulation, 2011,33 (12) :13-15 